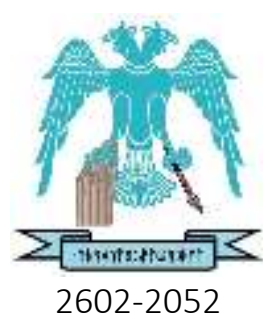

JOURNAL OF ENERGY SYSTEMS

VOLUME 2, ISSUE 4

DOI: $10.30521 /$ jes. 454193

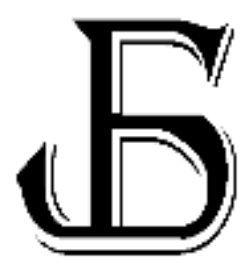

Research Article

\title{
A comparative CFD analysis of NACA0012 and NACA4412 airfoils
}

\author{
Mustafa Y1lmaz \\ Marmara University, İstanbul, Turkey, mustafa.yilmaz@marmara.edu.tr \\ ORCID: 0000-0001-6018-2211 \\ Hasan Koten \\ Istanbul Medeniyet University, Istanbul, Turkey, hasan.koten@medeniyet.edu.tr \\ ORCID: 0000-0002-1907-9420 \\ Erkan Çetinkaya \\ Marmara University, İstanbul, Turkey, cetinkayaerkan00@gmail.com \\ ORCID: 0000-0001-7545-2747 \\ Ziya Coşar \\ Marmara University, İstanbul, Turkey, ziya.cosar29@gmail.com \\ ORCID: 0000-0003-1017-3493
}

Arrived: 17.08.2018 Accepted: 24.09.2018 Published: 31.12.2018

\begin{abstract}
Wind energy has been seen as one of the most suitable sources of renewable energy. Wind energy is low cost when compared the other sources. Therefore, wind energy can gain an edge over the fossil-fired power plants. Aerodynamic efficiency of the airfoil is very crucial for aerodynamic efficiency of the wind turbine. The primary purpose of our study was to analyze the NACA0012 and NACA4412 airfoil at various attack angles with constant Reynolds number and to examine the effects of the symmetrical and asymmetrical profiles of the airfoil. Analysis of aerodynamic performance of NACA0012 and NACA4412 airfoil were performed with using ANSYS Fluent program. Also, lift coefficients and drag coefficients were calculated at various attack angles. According to calculations, optimum attack angles were found for each profile. Finally, NACA0012 and NACA4412 airfoils were discussed and reported in terms of their airfoil performances.
\end{abstract}

Keywords: Airfoil, NACA, Ansys fluent, CFD, Lift and drag coefficient.

Yılmaz M., Koten H., Çetinkaya, E, Coşar, Z., A comparative CFD analysis of

Cite this paper as: $\quad$ NACA0012 and NACA4412 airfoils. Journal of Energy Systems 2018; 2(4): 145159, DOI: 10.30521/jes.454193

(C) 2018 Published by peer-reviewed open access scientific journal, JES at DergiPark (www.dergipark.gov.tr/jes)

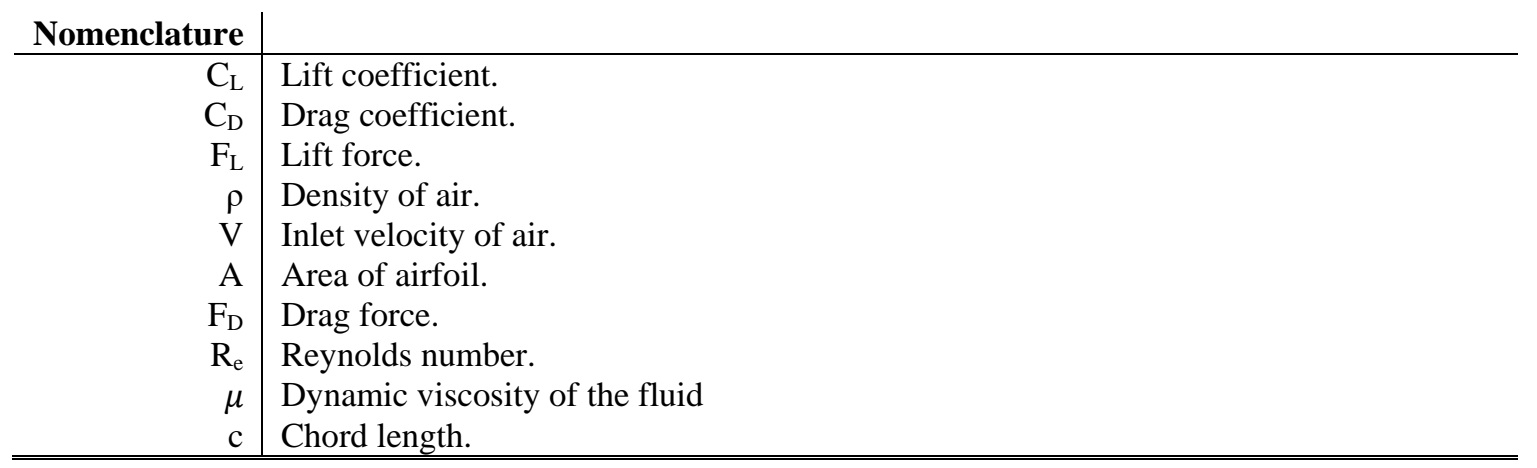




\section{INTRODUCTION}

An airfoil is the shape of a wing, blade of a propeller, rotor, or turbine, or sail as seen in cross-section to generate aerodynamic force. https://en.wikipedia.org/wiki/Airfoil. The main aim of airfoil's is that increase lift coefficient and decrease drag coefficient when exposed to a moving fluid. One of the most critical components of the wind turbine is the blade profile since it allows the kinetic energy to be converted to mechanical energy.

Computational fluid dynamics (CFD) has recently gained tremendous popularity and importance for researchers because it is now possible to achieve faster and more accurate results for various flow parameters around the geometry. CFD has found place in many major business sectors, which is in the field of aerospace, automobiles, marine and industrial processes, and components where fluid velocity and performance are important. In CFD calculations, it is easy to investigate the flow on airfoil geometry in detail. Also, it is cost effective and it provides gaining the work time instead of the experimental studies and have high costs.

In the recent studies, researchers examined NACA 4420 wind turbine airfoil profile [1-6]. Analyses are done by changing the blade angle with different wind speed by them. In addition, it is studied the Lift and Drag forces on a wind turbine blade for low Reynolds number and different angle of attack [7]. They examined NACA 0012 wind turbine airfoil profile and investigated NACA 0012 wind turbine airfoil profile [8]. NACA 0012 is analyzed Wind turbine airfoil profile with various angles of attack $\left(4,6,8,10\right.$ degree), keeping the Reynolds number constant of $10^{6}$. NACA 0015 profile is examined as wind turbine airfoil profile [9]. They studied the effect of angle of attack on the lift force, flow velocity profile, pressure profile, flow separation and wake formation. Some researchers are compared NACA 0015 and NACA 4415 wind turbine airfoil profiles [8]. They evaluated the dynamics of flow separation, lift, drag, pressure and velocity contour of NACA 0015 and NACA 4415 wind turbine airfoil profiles. They also are compared NACA 6409 and NACA 4412 wind turbine airfoil profiles [10]. They analyzed drag force, lift force as well as the overall pressure distribution over the airfoils. They changed the angle of attack and they observed variation in different properties. Another type profile is examined as S809 series wind turbine airfoil profile [11]. They performed all the analysis with using turbulence models like K-epsilon, Spalart-Allmaras and Viscous for the simulation S809 series airfoil at various angle of attacks (0 to 14 degree).

\section{THEORETICAL BACKGROUND}

In this parametric study, theoretical background and terminology can be explained using some definitions. One of main parameter is lift force and lift coefficient. Lift on a body is defined as the force on the body in a direction normal to the flow direction. Lift will only be present if the fluid incorporates a circulatory flow about the body such as that which exists about a spinning cylinder [8]. Lift coefficient $\left(C_{L}\right)$ is a dimensionless coefficient that relates the lift generated by airfoil, the dynamic pressure of the fluid flow around airfoil, and a reference area associated with the body [9]. The drag on a body in an oncoming flow is defined as the force on the body in a direction parallel flow direction [8]. Another parameter is Drag coefficient $\left(C_{D}\right)$ and it is a dimensionless quantity that is used to quantity the drag or resistance of an object in a fluid environment such as air for airfoil [10]. Angle of attack is the angle between chord line and relative wind as shown in Fig. 1. Besides that, airfoil dimensional parameters are shown in Fig. 2. 




Figure 1. Lift, Drag and Angle of Attack on the Airfoil



Figure 2. Airfoil design parameters.

The Reynolds number ( $\mathrm{Re})$ is an important dimensionless quantity in flow analysis used to help predict flow patterns in different fluid flow situations [12-18]. The flow unites with the airfoil on the leading edge and detaches on the trailing edge. Thus, the vortices may come out on the trailing edge. So, the Reynolds number must be considered. As the Reynolds number increases, the flow velocity increases and the tendency to turbulence also increases. Lift coefficient, drag coefficient and Reynold number are given in the below equations.

$$
\begin{gathered}
C_{L}=\frac{F_{L}}{1 / 2 \rho V^{2} A} \\
C_{D}=\frac{F_{D}}{1 / 2 \rho V^{2} A} \\
R_{e}=\frac{\rho V c}{\mu}
\end{gathered}
$$




\section{GEOMETRY and MESH GENERATION}

\subsection{Geometry of Airfoils}

In the following figures (i.e. Fig. 3), NACA0012 and NACA4412 profiles are shown as $2 \mathrm{~d}$ sketch, respectively. The coordinates of the airfoils were taken from NACA's airfoil database [13]. The coordinates of the airfoil were imported to ANSYS Workbench and to create the 2D geometry of the airfoils.
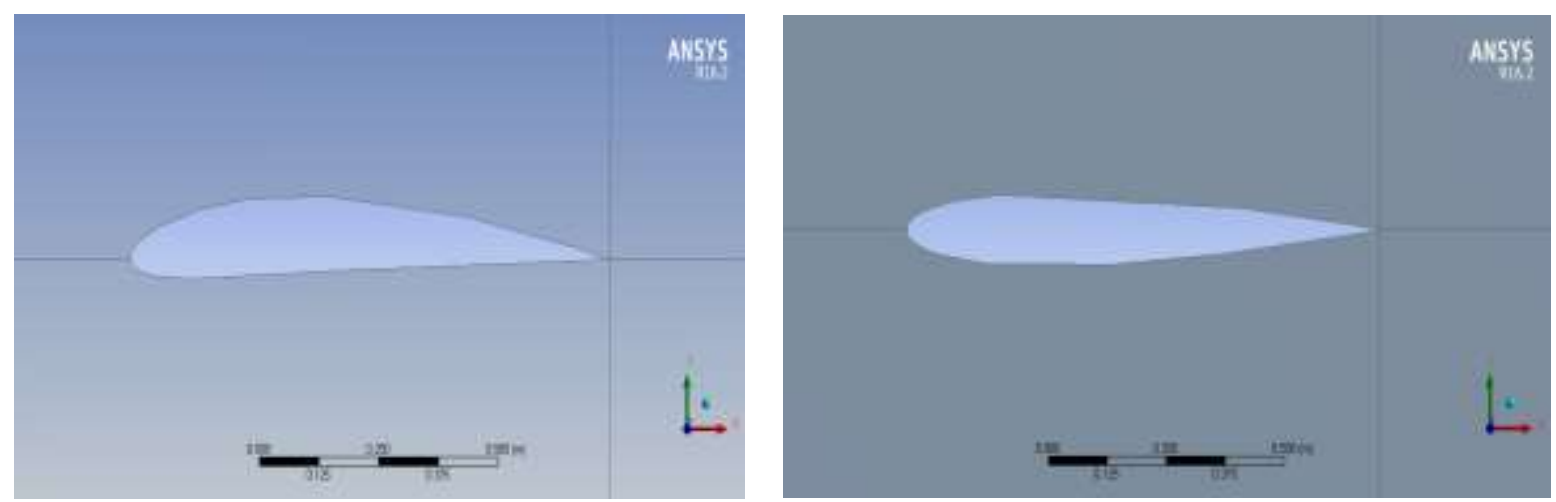

Figure 3. Geometry of NACA0O12 and NACA4412

\subsection{Mesh Generation of Airfoils}

In our study, it is important to catch wakes in leading edge and trailing edge. Therefore, to obtain reliable resolution after trailing edge, it had better attain tight cells in terms of mesh size. C-grid type is expressed as structural mesh at which another node follows each of nodes consecutively (Fig. 4).



Figure 4. C-type mesh construction

In present analysis, $\mathrm{C}$ type mesh with three-way velocity inlet method is used. The close view of geometry, mesh and boundary condition used in analysis is shown in Figs. 5 and 6, respectively. The density based implicit steady solver with Realizable k- $\varepsilon$ model turbulence model with second order upwind scheme is used for analysis. 


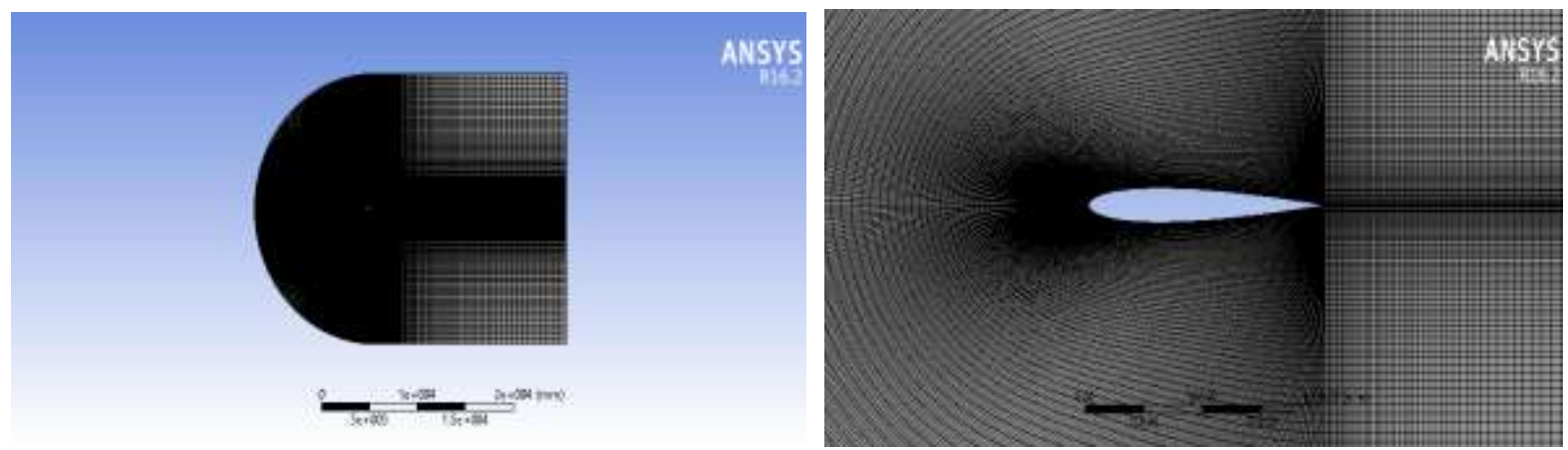

Figure 5. Mesh Generation of NACA0012
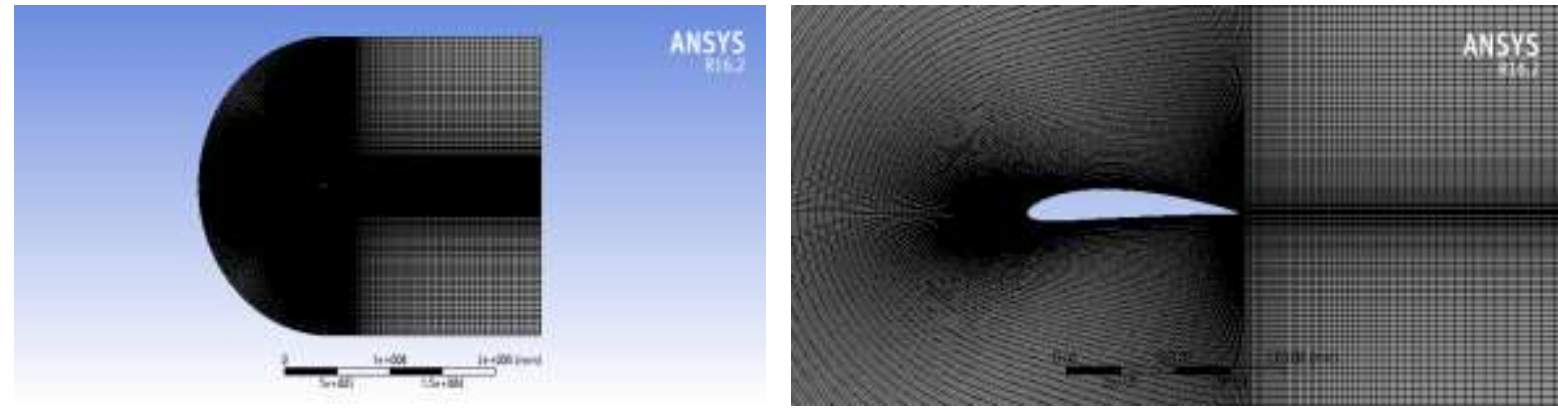

Figure 6. Mesh Generation of NACA4412

\subsection{Mesh Independency}

In our study, analyzes were performed by increasing the number of mesh from 30,000 to 100,000 . At the end of each analysis, the $C_{L} / C_{D}$ coefficients for a given angle of attack were calculated. When the increase in the change in $C_{L} / C_{D}$ coefficient becomes negligible, the optimum mesh number is determined. For this calculation, the table is shown below:

Table 1. Mesh Independency Table

\begin{tabular}{llll}
\hline MESH NUMBERS & \multicolumn{1}{c}{ CL } & \multicolumn{1}{c}{ CD } & CL/CD \\
\hline 30000 & 0.59118 & 0.020338 & 29.068 \\
40000 & 0.6082 & 0.018363 & 33.121 \\
50000 & 0.61613 & 0.017506 & 35.195 \\
60000 & 0.6199 & 0.017078 & 36.298 \\
70000 & 0.62251 & 0.016789 & 37.078 \\
80000 & 0.62473 & 0.016387 & 38.124 \\
90000 & 0.62583 & 0.016211 & 38.605 \\
100000 & 0.62718 & 0.015977 & 39.255 \\
\hline
\end{tabular}

For this results, mesh number was determined as 85,000 for the best solution.

\section{INPUTS and BOUNDARY CONDITIONS}

The analysis consists of flow around an airfoil at various angles of attack (4, 6,7, 8, 10, 12 degree). The inputs and boundary conditions are shown in the table below. 
Table 2. Inputs and Boundary Conditions Table

\begin{tabular}{lll}
\hline No & Input & Value \\
\hline 1 & Fluid Type & Air \\
2 & Velocity of Flow & $8.575[\mathrm{~m} / \mathrm{s}]$ \\
3 & Operating Pressure & $101325[\mathrm{~Pa}]$ \\
4 & Density of Fluid & $1.1767\left[\mathrm{~kg} / \mathrm{m}^{3}\right]$ \\
5 & Reynolds Number & $10^{6}$ \\
6 & Chord Length & $1[\mathrm{~m}]$ \\
7 & Operating Temperature & $277[\mathrm{~K}]$ \\
8 & Angles of Attack & $2\left[^{\circ}\right], 4\left[^{\circ}\right], 6\left[^{\circ}\right], 7\left[^{\circ}\right], 8\left[^{\circ}\right], 10\left[^{\circ}\right], 12\left[^{\circ}\right]$ \\
9 & Model & Realizable $k-\varepsilon$ \\
10 & Viscosity & $1.009 \times 10^{-5}[\mathrm{~kg} / \mathrm{ms}]$ \\
\hline
\end{tabular}

\section{RESULT and DISCUSSION}

\subsection{Contours of Velocity Magnitude}

In the following figures (i.e. Figs. 7-12), velocity contours at various attack angles $\left(4^{\circ}, 6^{\circ}, 7^{\circ}, 8^{\circ}, 10^{\circ}, 12^{\circ}\right)$ were obtained for NACA0012 and NACA4412, where CFD simulations are shown. At the leading edge, we can notice the stagnation point where the flow velocity is almost zero for each airfoil. As the flow velocity accelerates over the upper surface of the airfoil, the velocity of the flow is completely opposite for lower surface of each airfoil.
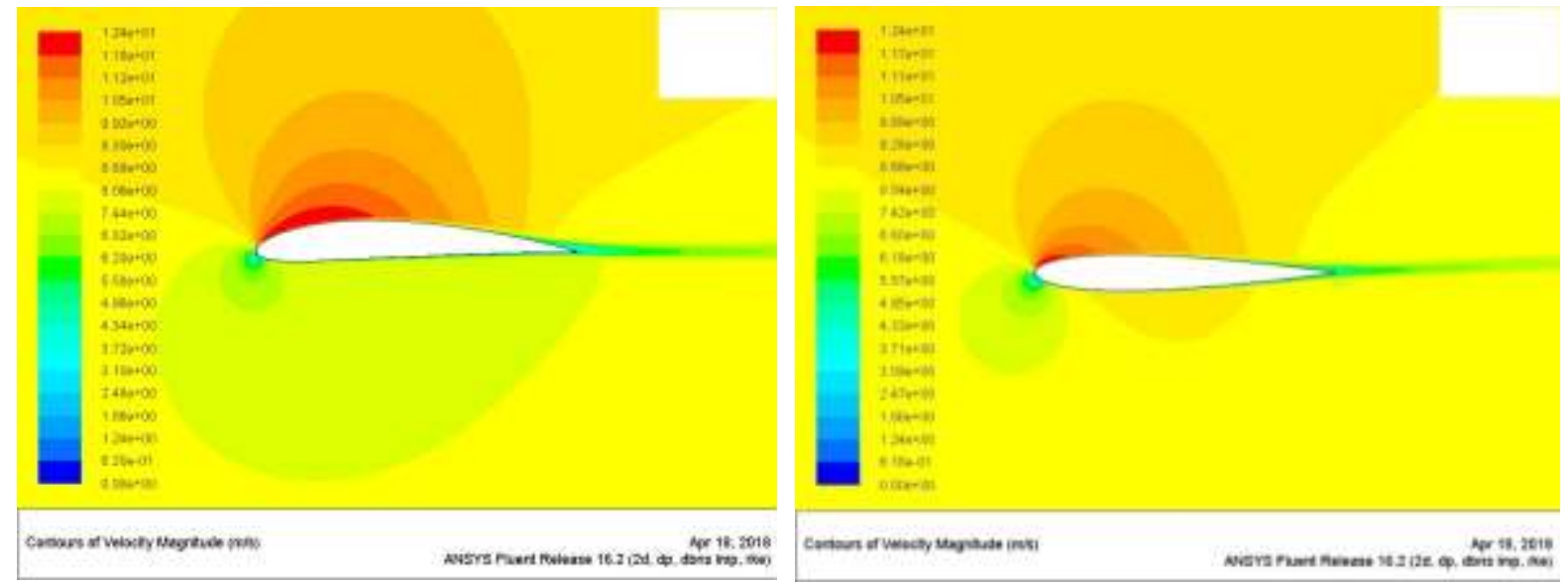

Figure 7. Velocity contours of NACA0012 and NACA4412 at $4^{\circ}$ of angle of attack 

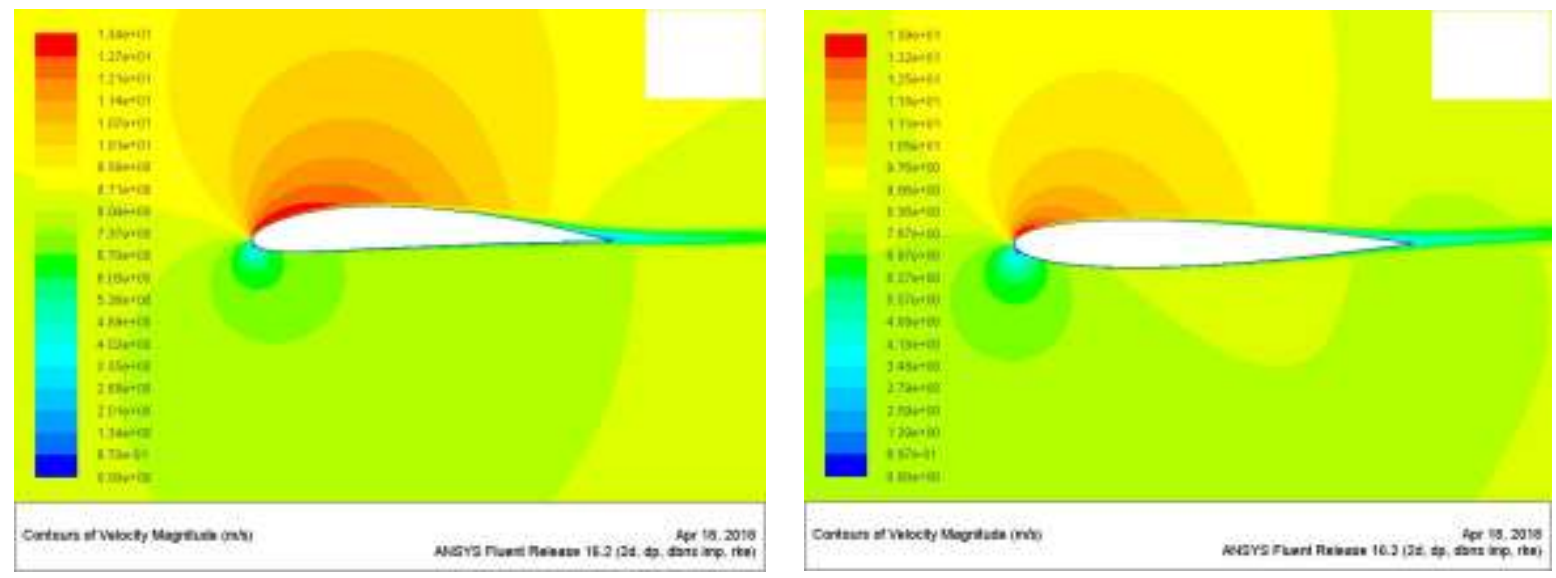

Figure 8. Velocity contours of NACA0012 and NACA4412 at $6^{\circ}$ of angle of attack
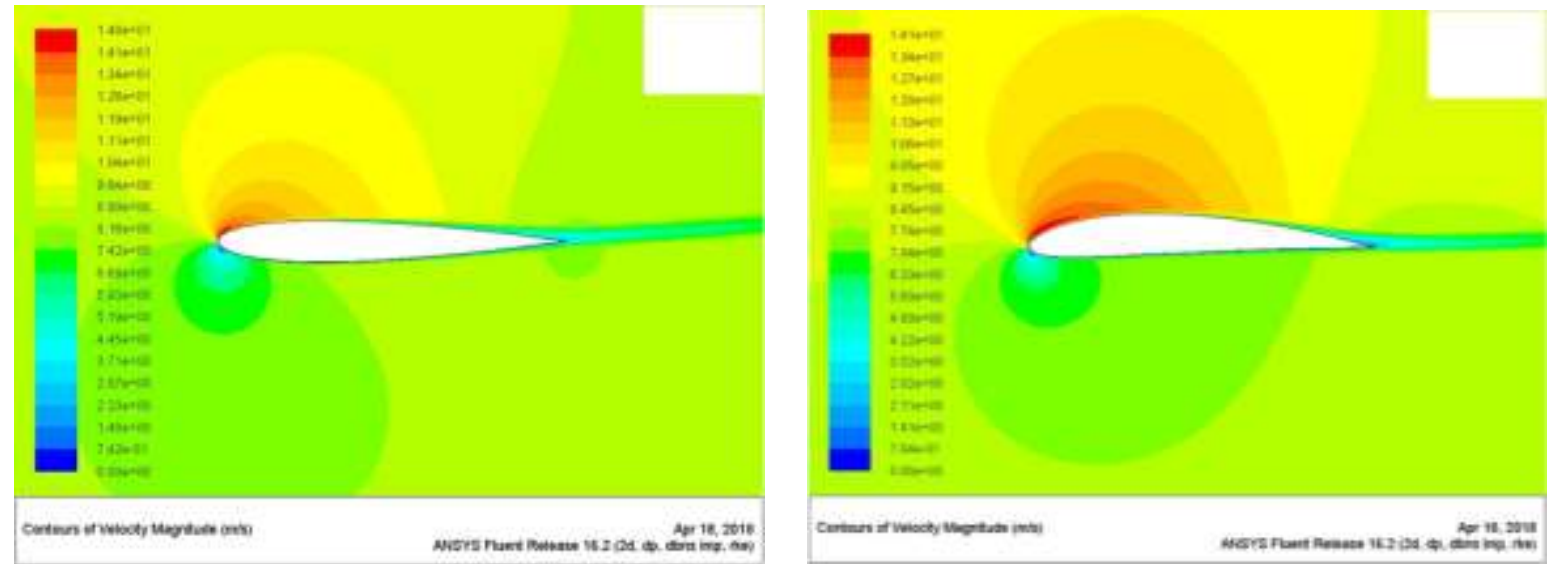

Figure 9. Velocity contours of NACA0012 and NACA4412 at $7^{\circ}$ of angle of attack
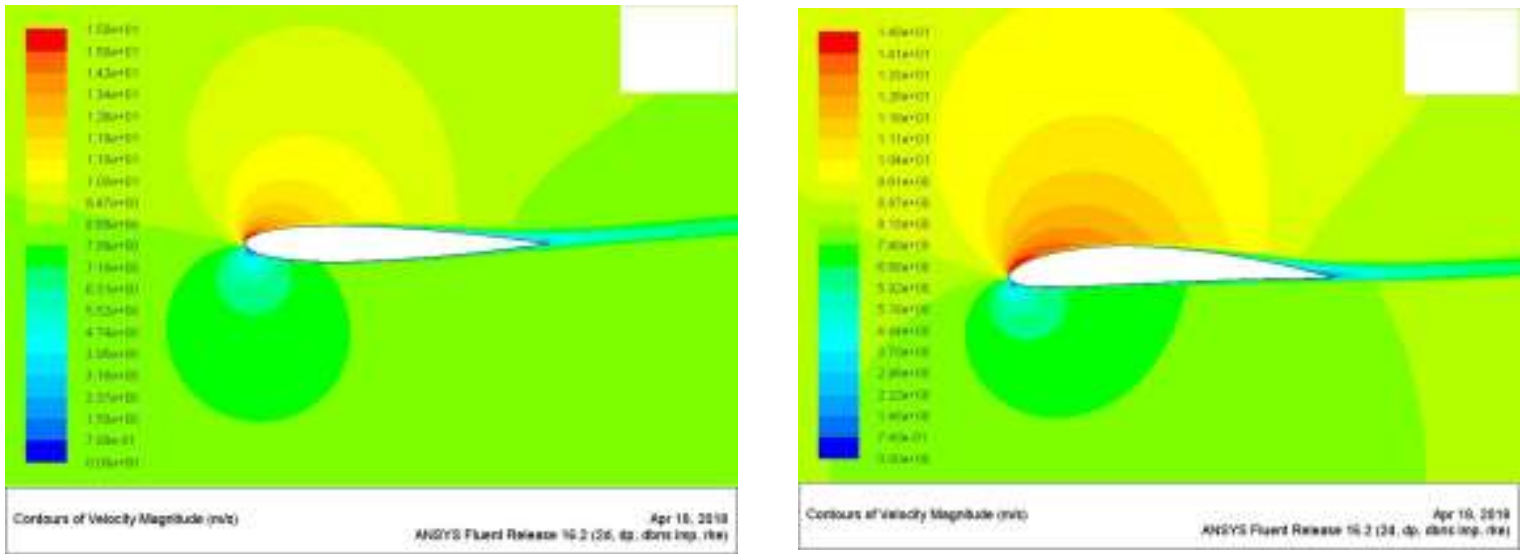

Figure 10. Velocity contours of NACA0012 and NACA4412 at $8^{\circ}$ of angle of attack 



Figure 11. Velocity contours of NACA0012 and NACA4412 at $10^{\circ}$ of angle of attack
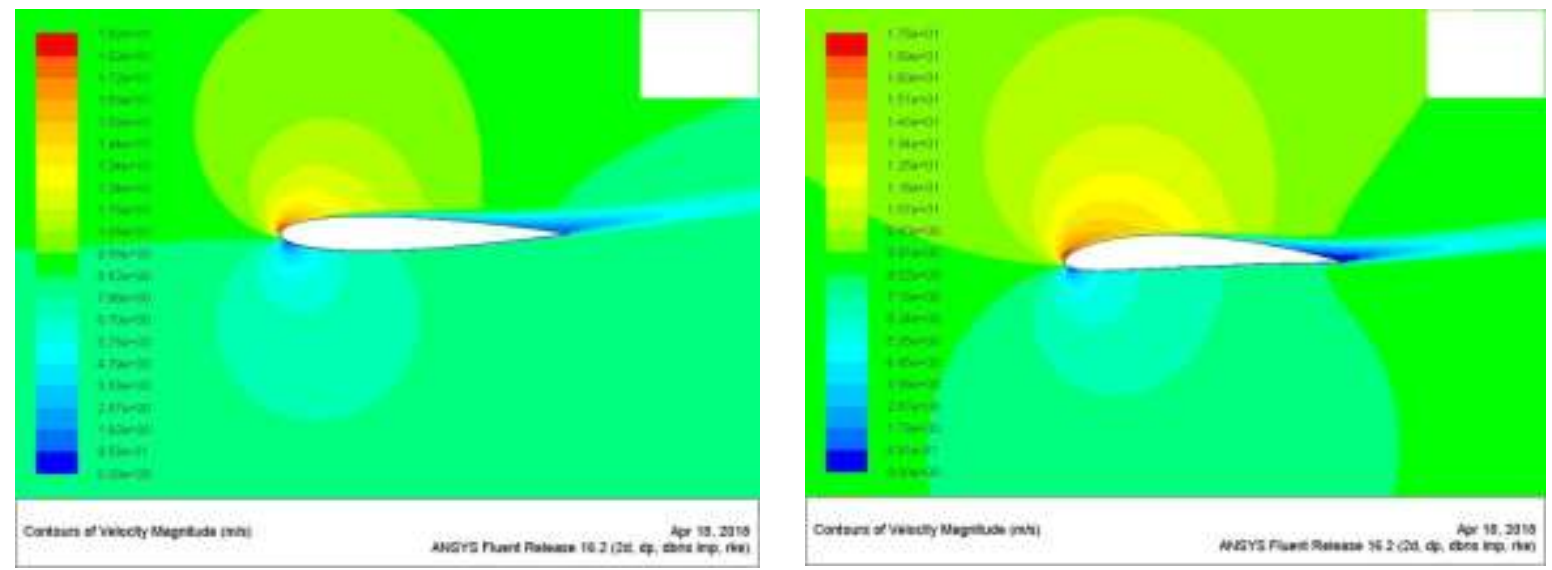

Figure 12. Velocity contours of NACA0012 and NACA4412 at $12^{\circ}$ of angle of attack

\subsection{Static Pressure Contours}

In the following figures (i.e. Figs. 13-18), static pressure contours at various attack angles $(4,6,7,8,10$ ,12 ) were obtained for NACA0012 and NACA4412 where CFD simulations are shown. We can see that the flow velocity on the upper side of each airfoil is accelerated; the flow velocity on the lower side is opposite. According to Bernoulli's principle, the upper surface will encounter low pressure and the lower surface will encounter higher pressure. For this reason, the value of the lift coefficient will increase and the value of the drag coefficient will increase, but the increase in drag is less than the increase in lift. The pressure on the lower surface of each airfoil is greater than the pressure on the upper surface. Each airfoil is pushed upward effectively into the incoming flow stream. 

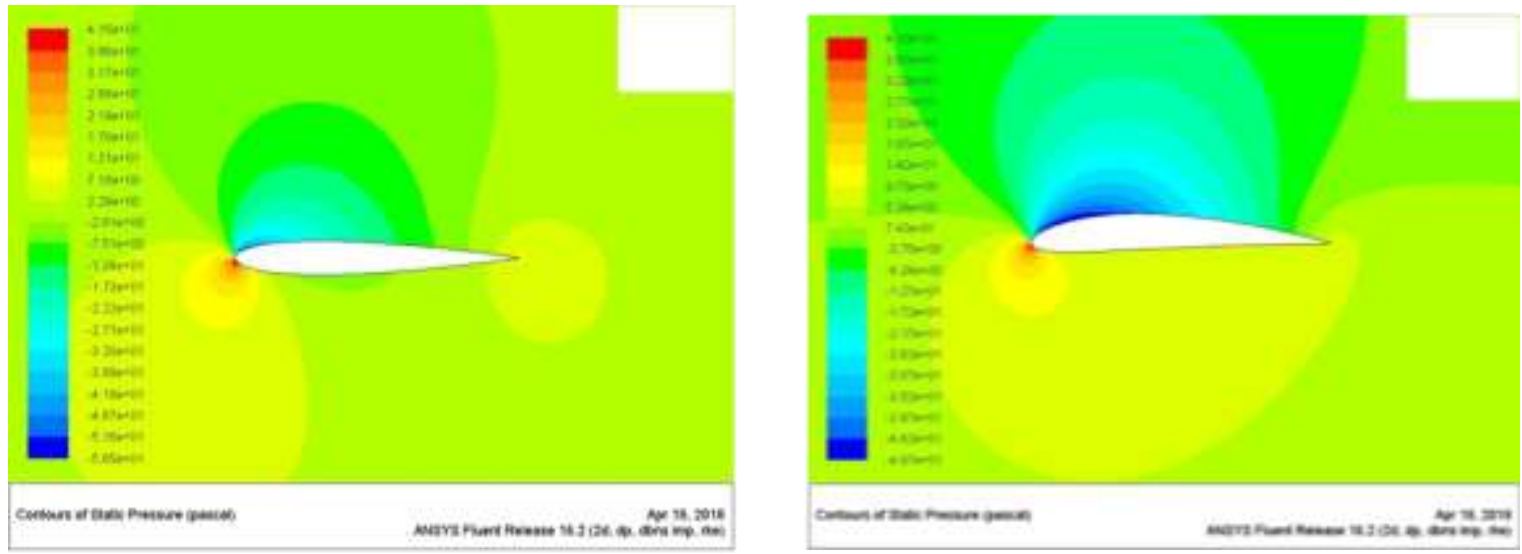

Figure 13. Pressure contours of NACA0012 and NACA4412 at $4^{\circ}$ of angle of attack
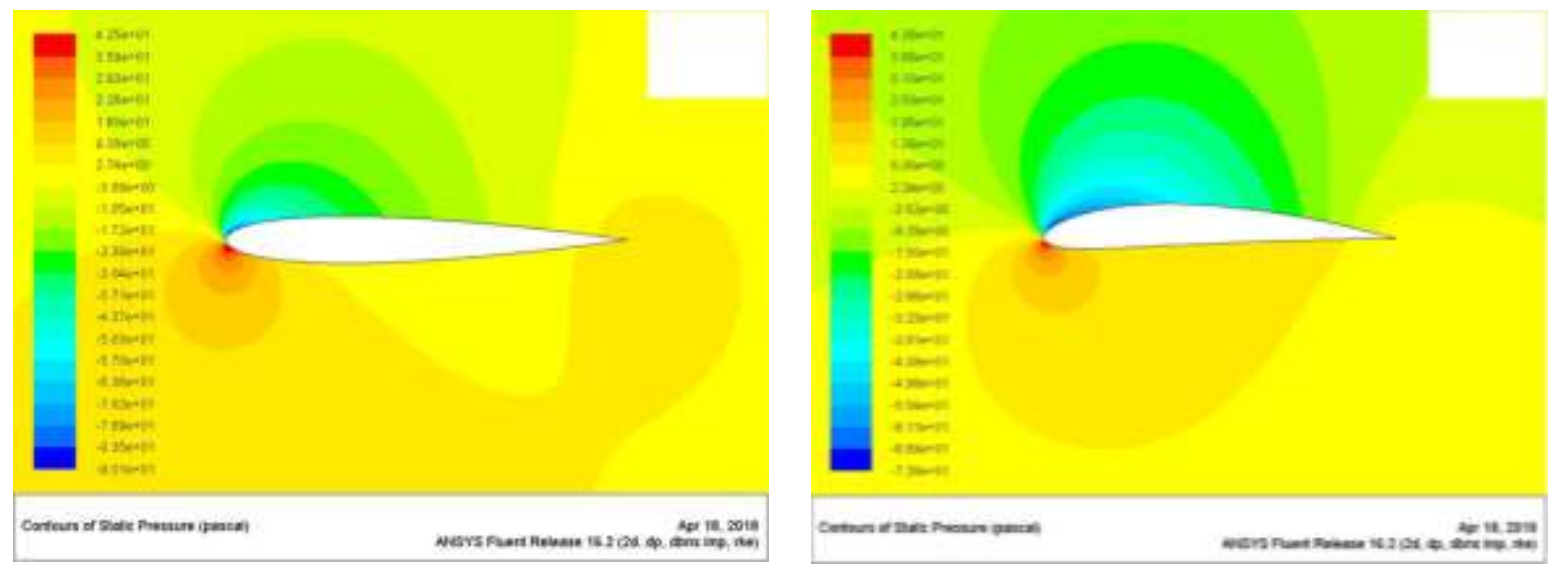

Figure 14. Pressure contours of NACA0012 and NACA4412 at $6^{\circ}$ of angle of attack


Figure 15. Pressure contours of NACA0012 and NACA4412 at $7^{\circ}$ of angle of attack 

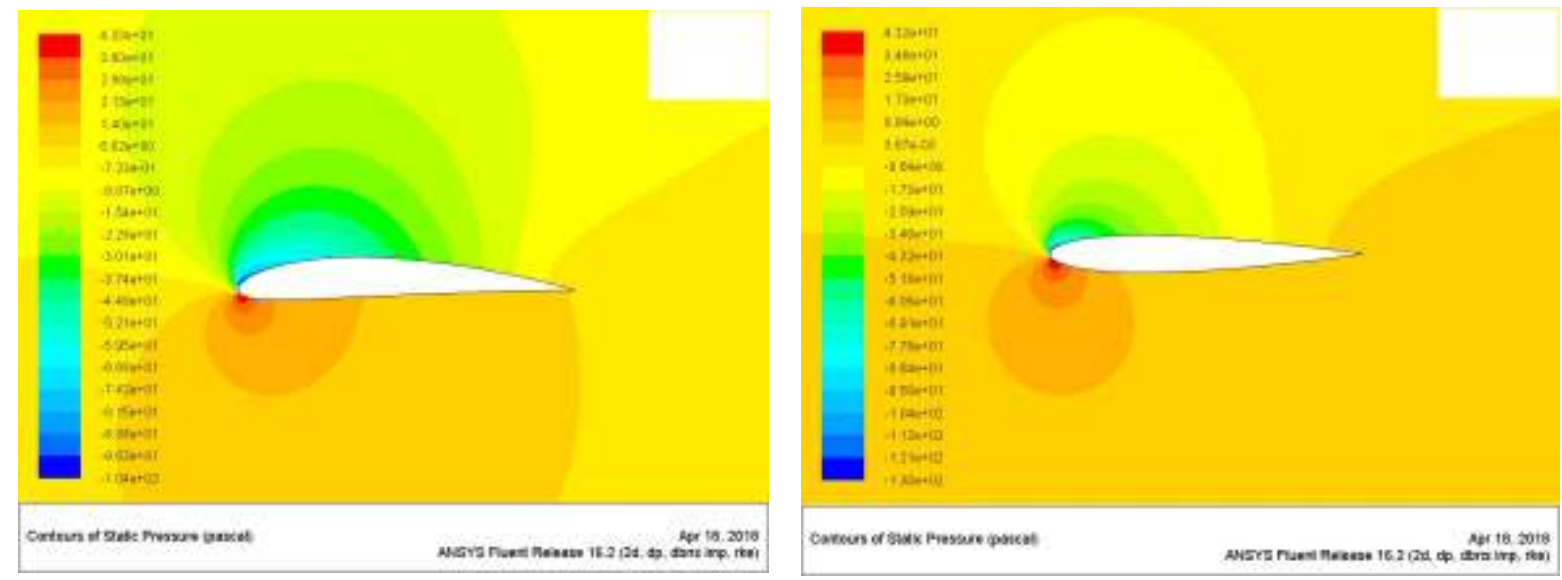

Figure 16. Pressure contours of NACA0012 and NACA4412 at $8^{\circ}$ of angle of attack
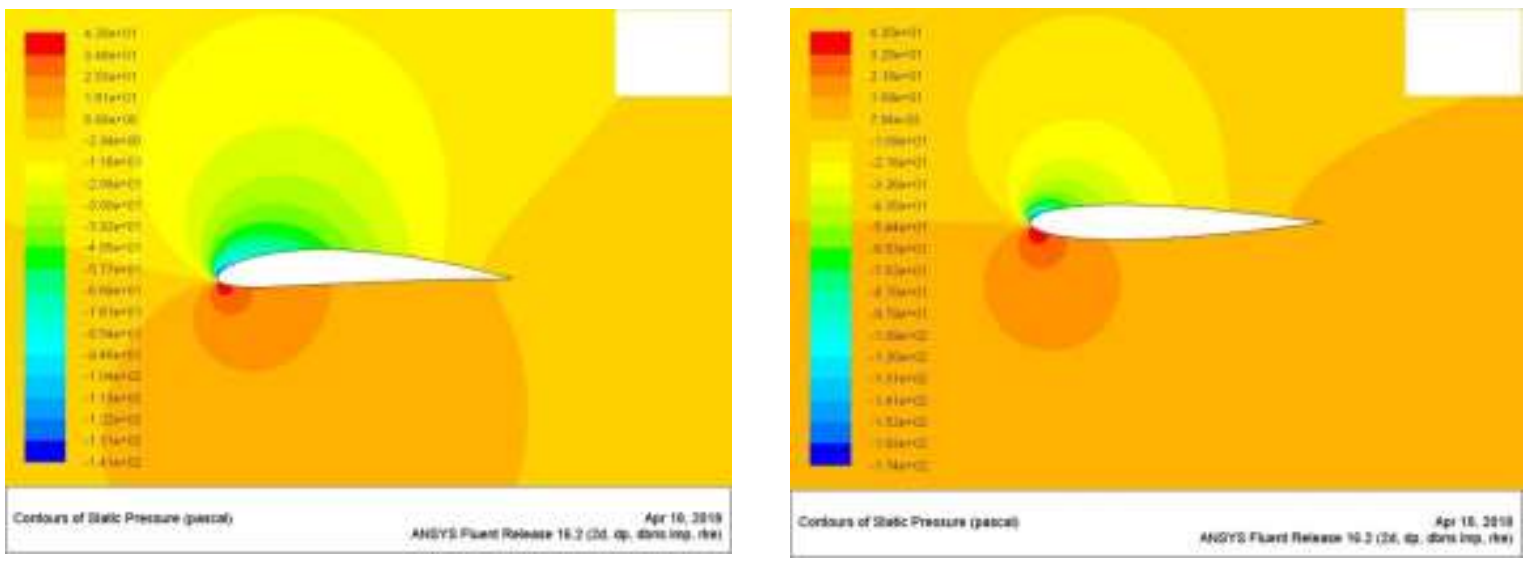

Figure 17. Pressure contours of NACA0012 and NACA4412 at $10^{\circ}$ of angle of attack
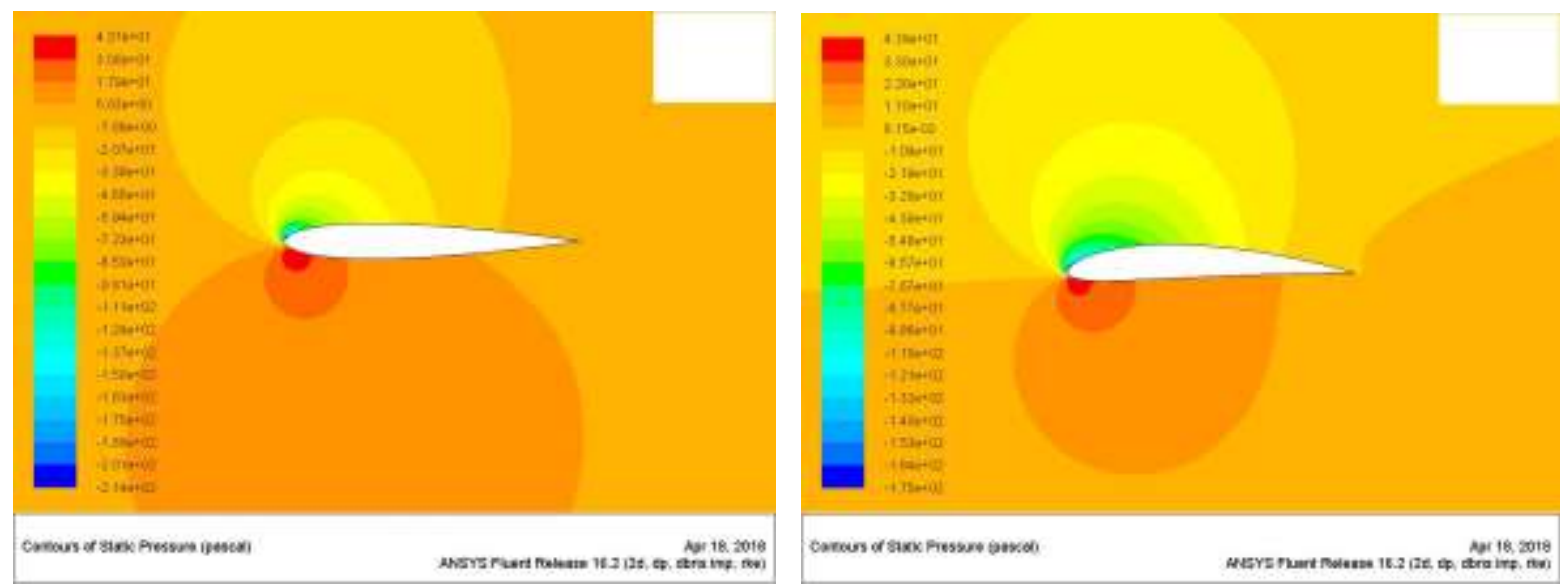

Figure 18. Pressure contours of NACA0012 and NACA4412 at $12^{\circ}$ of angle of attack 


\subsection{Distribution of Pressure Coefficient}

In the following figures (i.e. Figs.19-24), pressure coefficient distributions of the NACA0012 and NACA4412 airfoils at different attack angles is shown. It can be seen that the pressure coefficient varies greatly under different attack angles. Upper surface of the airfoil has negative pressure coefficient and the lower surface of airfoil was positive, so the lift force of the airfoil is upwards. When the attack angle increases, pressure coefficient difference between the lower and upper surface also increases. It is also found that the pressure difference coefficient is much lower at the trailing edge when it is much larger at the leading edge. Thus it also shows that the airfoil's lift force is mainly generated at the front edge.



nemereconover



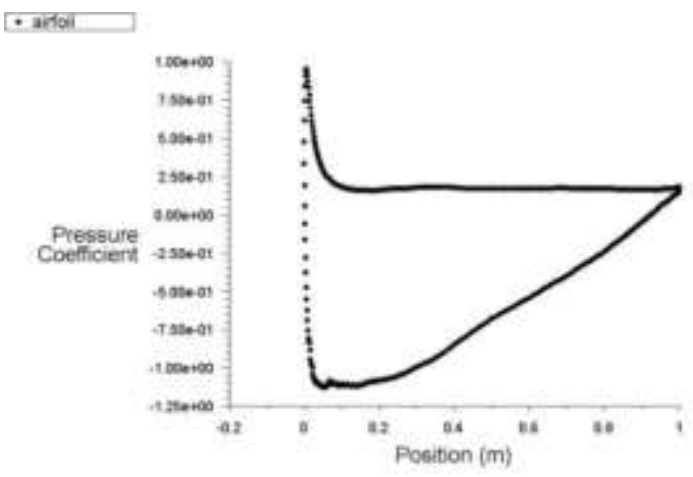



Figure 19. Pressure coefficient of NACA0012 and NACA4412 at $4^{\circ}$ angle of attack


Figure 20. Pressure coefficient of NACA0012 and NACA4412 at $6^{\circ}$ angle of attack 

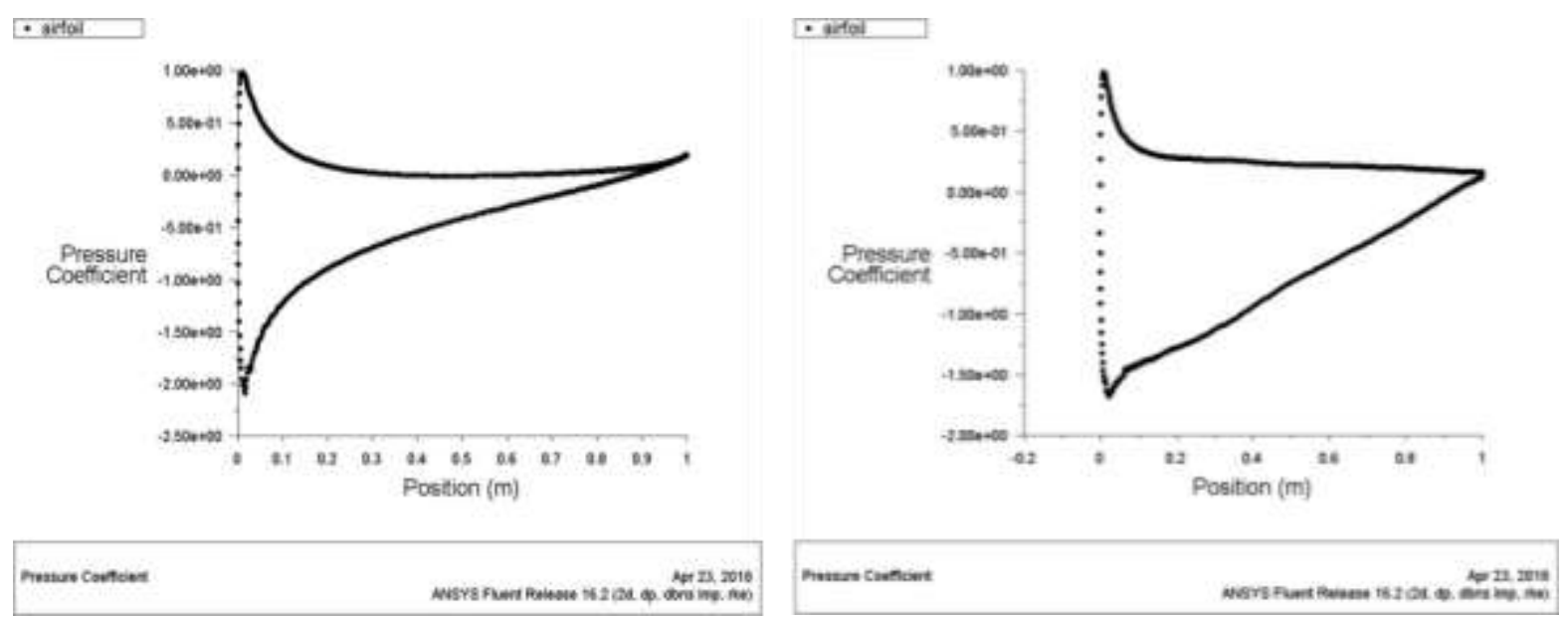

Figure 21. Pressure coefficient of NACA0012 and NACA4412 at $7^{\circ}$ angle of attack
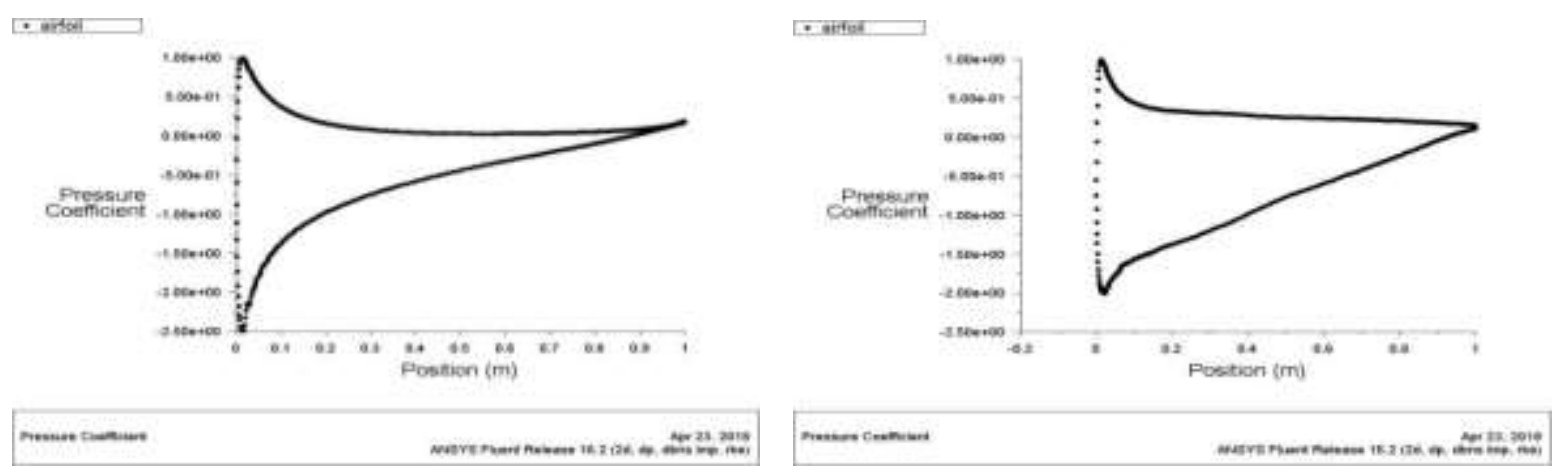

Figure 22. Pressure coefficient of NACA0012 and NACA4412 at $8^{\circ}$ angle of attack


Figure 23. Pressure coefficient of NACA0012 and NACA4412 at $10^{\circ}$ angle of attack 



Figure 24. Pressure coefficient of NACA0012 and NACA4412 at $12^{\circ}$ angle of attack

\subsection{Curves of Lift and Drag Coefficient}

The curves of lift and drag coefficient are computed at various angles of attack using the Realizable $k-\varepsilon$ turbulence model for NACA0012 and NACA4412.

Table 3. $C_{L} / C_{D}$ Values with Changing Angle of Attack for NACA0012

\begin{tabular}{cccc}
\hline \multicolumn{4}{c}{ NACA0012 } \\
Angle of Attack $\left(^{\circ}\right)$ & $\mathrm{C}_{\mathrm{L}}$ & $\mathrm{C}_{\mathrm{D}}$ & $\mathrm{C}_{\mathrm{L}} / \mathrm{C}_{\mathrm{D}}$ \\
\hline 4 & 0.42283 & 0.013677 & 30.91540543 \\
6 & 0.62568 & 0.016235 & 38.53895904 \\
7 & 0.72368 & 0.018122 & 39.93378214 \\
8 & 0.81816 & 0.020519 & 39.87328817 \\
10 & 0.99066 & 0.027409 & 36.14360247 \\
12 & 1.11060 & 0.038996 & 28.47984409 \\
\hline
\end{tabular}

Table4. CL/CD Values with Changing Angle of Attack for NACA4412

\begin{tabular}{clll}
\hline & \multicolumn{4}{l}{ NACA4412 } & \\
Angle of Attack $\left({ }^{\circ}\right)$ & CL & CD & CL/CD \\
\hline 4 & 0.83354 & 0.016476 & 50.5911629 \\
6 & 1.0281 & 0.019713 & 52.15340131 \\
7 & 1.1211 & 0.021827 & 51.36299079 \\
8 & 1.209 & 0.024379 & 49.59186185 \\
10 & 1.3588 & 0.030955 & 43.89597803 \\
12 & 1.45 & 0.040606 & 35.70900852 \\
\hline
\end{tabular}




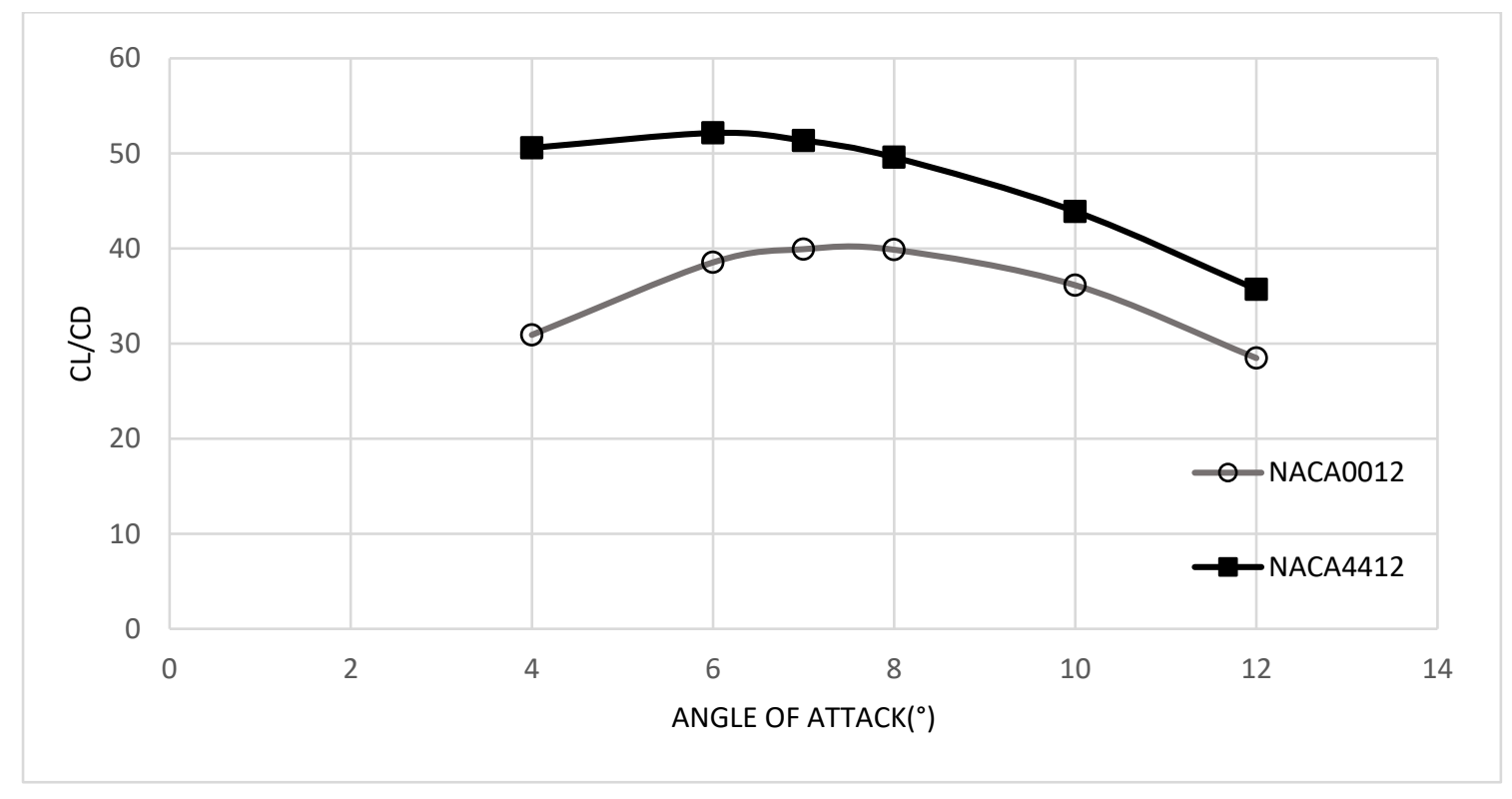

Figure 25. $C_{L} / C_{D}$ Values for Naca0012 and Naca4412 Vs Angle of Attack

\section{CONCLUSION}

Analysis of aerodynamic performance of NACA0012 and NACA4412 airfoil have been performed at various attack angles $\left(4^{\circ}, 6^{\circ}, 7^{\circ}, 8^{\circ}, 10^{\circ}, 12^{\circ}\right)$ with constant $10^{6}$ Reynolds number, and using the Realizable $k-\varepsilon$ turbulence model. These calculations will support the calculating of a whole turbine power coefficient. These airfoils can also be applied in different turbine's stations or radial positions. It can be seen that from the velocity magnitude figures, the upper surface's flow velocity is higher than the lower surface's flow velocity and flow velocity of the upper surface increases with increasing attack angles. It can be seen that from the static pressure contours, static pressure of the lower surface of the airfoil increases with increasing attack angles. It can be seen that from the pressure coefficient figures, upper surface of the airfoil has negative pressure coefficient and the lower surface of airfoil was positive, so the lift force of the airfoil is upwards. It can be seen that from the $C_{L}$ and $C_{D}$ values tables, $C_{L}$ and $C_{D}$ values increases with increasing attack angles. When the $C_{L} / C_{D}$ values are examined, it is seen that $7^{\circ}$ angle of attack is the optimum value for NACA0012. When the $C_{D} / C_{D}$ values are examined, it is seen that $6^{\circ}$ angle of attack is the optimum value for NACA4412.

When the static pressure contours of NACA0012 and NACA4412 are examined, it can be seen that NACA4412 will have greater pressure gradient at every angle of attack. When the velocity magnitude contours of NACA0012 and NACA4412 are examined, it can be seen that the lower surface of the asymmetric airfoil (NACA4412) provides more lift than the lower surface of symmetrical airfoil (NACA0012). When the pressure coefficient of NACA0012 and NACA4412 is examined it is realized that area of negative pressure for NACA4412 is larger than NACA0012. When the static pressure contours, velocity magnitude contours, pressure coefficient, and the lift and drag coefficients with the change of angle of attack, it can be noticed that the cambered airfoil NACA4412 is more efficient shape than symmetrical airfoil NACA0012 at every attack angles. 


\section{REFERENCES}

[1] Chandrala, M., Aerodynamic Analysis of Horizontal Axis Wind Turbine Blade. International Journal of Engineering Research and Applications, 2012; (IJERA) ISSN: 2248-9622. Vol. 2, Issue6, pp.1244-1248.

[2] Patil, S., Computational Fluid Dynamics Analysis of Wind Turbine Blade at Various Angles of Attack and Different Reynolds Number. International Conference on Computational Heat and Mass Transfer, Procesia Enginering. 2015; 127, pp.1363-1369.

[3] Dash, A., CFD Analysis of Wind Turbine Airfoil at Various Angles of Attack. IOSR Journal of Mechanical and Civil Engineering (IOSR-JMCE) e-ISSN: 2278-1684, p-ISSN: 2320-334X. Volume 13, Issue 4 Ver. II, pp.18-24.

[4] Reddy, A., A Brief Research, Study, Design and Analysis on Wind turbine. Journal of Modern Engineering Research (IJMER), 2015; Vol. 5 Issue10.

[5] Rubel, R.I., Uddin, M.K. Islam, M.Z. and Rokunuzzaman, M., Comparison of Aerodynamics Characteristics of NACA 0015 \& NACA 4415. Preprints 2016.

[6] Hossain, S., A Comparative Flow Analysis of Naca 6409 and Naca 4412 Aerofoil. IJRET: International Journal of Research in Engineering and Technology, 2014; eISSN: 2319-1163 pISSN: 2321-7308. Volume 3, Issue 10.

[7] Najar, A., Blade Design and Performance Analysis of Wind Turbine. International Journal of ChemTech Research CODEN, 2013; IJCRGG ISSN: 0974-4290. Vol.5, No.2, pp 1054-1061.

[8] Burton, T., Jenkins, N, Sharpe, D. and Bossanyi, E. Wind Energy Handbook. Chichester, UK: John Wiley \& Sons, 2011; 65-67.

[9] Şahin, İ. and Acir, A., Numerical and Experimental Investigations of Lift and Drag Performances of NACA 0015 Wind Turbine Airfoil, International Journal of Materials, Mechanics and Manufacturing, 2015; Vol. 3, No. 1.

[10] Coles, D. and Alan, J., Flying-Hot-wire Study of Flow Past an NACA 4412 Airfoil at Maximum Lift, AIAA Journal, 1979; Vol. 17, No. 4, pp. 321-329.

[11] Alley, R.N., Warren, F.P. and Spall, R., Predicting Maximum Lift Coefficient for Twisted Wings Using Computational Fluid Dynamics. Journal of Aircraft. 2007; 890-898.

[12] Sheldahl, R. E., and Klimas, P. C., Aerodynamic characteristics of seven symmetrical airfoil sections through 180-degree angle of attack for use in aerodynamic analysis of vertical axis wind turbines. United States: N. p., 1981.

[13] Panigrahi, D.C. and Mishra D.P., CFD Simulations for the Selection of an Appropriate Blade Profile for Improving Energy Efficiency in Axial Flow Mine Ventilation Fans", Journal of Sustainable Mining, 2014; Volume 13, Issue 1, Pages 15-21, ISSN 2300-3960.

[14] Chen, F., Zhang, L., Huai, X., Li, J., Zhang, H. and Liu, Z., Comprehensive performance comparison of airfoil fin PCHEs with NACA 00XX series airfoil, Nuclear Engineering and Design, 2017; Volume 315, Pages 4250.

[15] Cui, X., Guo, J., HuaF[i, X., Cheng, K., Zhang, H. and Xiang, M., "Numerical study on novel airfoil fins for printed circuit heat exchanger using supercritical CO2," International Journal of Heat and Mass Transfer, 2018; Volume 121, Pages 354-366.

[16] Christopher, J. and Krus, J., Lift Coefficient Predictions for Delta Wing Under Pitching Motions, 32nd AIAA Fluid Dynamics Conference and Exhibit, Fluid Dynamics and Co-located Conferences. 24-26 June 2002, St. Louis, Missouri, 158-164.

[17] Alexander, W., Application of CFD to wake/aerofoil interaction noise - A flat plate validation case, 7th AIAA/CEAS Aeroacoustics Conference and Exhibit, Aeroacoustics Conferences, 28 - 30 May 2001, Maastricht, Netherlands, 50-61.

[18] Henry, G., Steven, H., and James, S., 23\% Circulation Controlled Elliptical Airfoil Modeled Using CFD, 20th AIAA Computational Fluid Dynamics Conference, Fluid Dynamics and Co-located Conferences, 27 - 30 June 2011, Honolulu, Hawaii, 221-229. 